\title{
11. Is there a cultural explanation for Indigenous violence? A second look at the NATSISS
}

\author{
Don Weatherburn and Lucy Snowball
}

Violence is a chronic problem among Indigenous Australians. The 2002 Australian Bureau of Statistics (ABS) National Aboriginal and Torres Strait Islander Social Survey (NATSISS) found that 22 per cent of Australia's Indigenous population (aged 15 years and over) had been victims of physical or threatened violence in the 12 months preceding the survey (ABS 2004). The 2008 NATSISS survey (ABS 2010) showed a very similar result (23\%). It is impossible to obtain comparable figures on the prevalence of physical or threatened assault among non-Indigenous people. There is little doubt, however, that serious violence is far more prevalent among Indigenous Australians. In their study of New South Wales hospitalisation data, Clapham, Stevenson and Lo (2006) found that Aboriginal people are five times more likely to be hospitalised for interpersonal violence than non-Aboriginal people. The majority of this violence, of course, is intra- rather than inter-communal (Fitzgerald and Weatherburn 2001; Harding et al. 1995: 29).

At least four different theories have been put forward to explain the high level of violence amongst Australia's Indigenous population. The first, exemplified in the work of Sutton (2001, 2009), Langton (1988) and Martin (1992) asserts that the high level of violence found in Indigenous communities is (at least partly) a vestige of traditional Aboriginal culture. Sutton (2001: 152), for example, points out that archaeological records of pre-historic (Aboriginal) remains reveal a much higher incidence of 'defensive' injuries to the bones of Aboriginal women than to the bones of Aboriginal men, and argues that early versions of what is now called family violence or community violence were widespread under 'traditional' conditions. He contends that recent ethnographies by trained anthropologists leave little doubt that family and community violence were widespread and frequent in Australia prior to white settlement, arguing that '...those with the most recent experience of being drawn into contact with the wider world and with alcohol seem to be facing the greatest problems of interpersonal violence' (Sutton 2009: 101). Langton (1988) and Martin (1992) have also commented on the ritualistic and socially accepted nature of much of the violence in Aboriginal communities. According to Martin (1992), for example, while some contemporary fighting and violence can be attributed to 'intervention by the wider society', violence and fighting are 'also deeply rooted 
in cultural values' (Martin 1998: 16). Reser (1990: 30) has made a similar point, arguing that Aboriginal people differ markedly from non-Aboriginal people in their willingness to give expression to anger.

The second theory, patterned after social disorganisation theory (Sampson, Raudenbush and Earls 1997) attributes Indigenous violence to breakdown of Indigenous informal social controls following colonisation and dispossession. The Royal Commission into Aboriginal Deaths in Custody took this view, arguing that 'disruption, intervention and institutionalisation' had undermined Aboriginal family and kinship structures, thereby making it difficult for parents and elders to inculcate traditional social norms (Commonwealth of Australia 1991: paras 14.4.39-14.4.43). The third theory, implicit in the work of Devery (1991) and Gale, Bailey-Harris and Wundersitz (1990), sees Indigenous violence as a response to social and economic deprivation. The fourth, patterned after lifestyle/routine activity theory (Cohen and Felson 1979), asserts that the high levels of Indigenous violence are a comparatively recent phenomenon, generated by passive welfare dependence and/or alcohol abuse (Hughes and Warin 2005; Pearson 2001).

Snowball and Weatherburn used data from the 2002 NATSISS (ABS 2004) to conduct a preliminary assessment of these theories (Snowball and Weatherburn 2008). They argued that if the high level of Indigenous violence is a vestige of traditional Aboriginal culture, one might expect to find higher levels of violence among those who:

- lived on traditional homelands

- identified with a clan or spoke an Indigenous language, and

- had difficulties speaking English.

If the social disorganisation theory perspective on Indigenous violence were correct, one would expect higher rates of violent victimisation amongst Indigenous Australians who:

- are not socially involved in their communities ${ }^{1}$

- are sole parents

- have high rates of geographic mobility (as measured by the number of times they moved house)

- are members or have relatives who are members of the stolen generation.

\footnotetext{
1 Social involvement includes: recreational or cultural group activities; community or special interest group activities; church or religious activities; going out to a cafe, restaurant or bar; involvement in sport or physical activities; attendance at sporting event as a spectator; visiting a library, museum or art gallery; attending movies, theatre or concert; visiting a park, botanic gardens, zoo or theme park; attendance at Aboriginal and Torres Strait Islander Commission (ATSIC) or native title meetings; attending a funeral, ceremony or festival; and fishing or hunting in a group.
} 
If Indigenous economic and social deprivation is the key driver of Indigenous violence, one would expect to see higher rates of Indigenous victimisation amongst those who:

- $\quad$ are socially stressed ${ }^{2}$

- are unemployed, or if employed work within a Community Development Employment Projects (CDEP) scheme ${ }^{3}$

- have experienced financial stress ${ }^{4}$

- left school early

- live in a crowded household ${ }^{5}$

- live in a household with more than two dependent children

- have been charged with a criminal offence as a child.

Finally, if lifestyle/routine activity theory is correct then one would expect higher rates of violent victimisation among those who live with or near potential offenders; who cannot readily escape from potential offenders; or who have a lifestyle (e.g. heavy drinking) that exposes them to violence. In terms of NATSISS variables, this would lead one to expect higher rates of violent victimisation amongst those who:

- have a severe or moderate disability and are therefore more vulnerable to attack (Wilson et al. 1996)

- live in an area with neighbourhood problems

- consume alcohol in a high risk manner ${ }^{6}$

- use illicit substances or misuse licit substances ${ }^{7}$

- reside with a person who has been charged with an offence

- do not have access to a motor vehicle (and therefore find it more difficult to escape from or avoid violent situations).

Snowball and Weatherburn (2008) found strong support for lifestyle/routine activity theories, moderate support for social disorganisation and social deprivation theories but little support for cultural theories of Indigenous violence. High-risk alcohol consumption has the highest odds ratio (2.23). Significant effects were also found for most other lifestyle/routine activity

2 The stressors included in this variable were: divorce or separation; death of a family member or close friend; serious accident; mental illness; witness to violence; gambling problem; pressure to fulfil cultural responsibilities; and discrimination or racism.

3 This is labour market program in which Indigenous Australians performed work intended to benefit (develop) their community in return for welfare payments.

4 This was measured by whether the household had days without money for basic living expenses in the preceding 12 months.

5 We defined crowded as households where the number of people exceeded twice the number of bedrooms.

6 The ABS classify this using the Australian Alcohol Guidelines.

7 Note that due to data quality concerns in the 2002 NATSISS the ABS only released information on this variable for respondents living in non-remote areas. 
variables, including: residing in an area with neighbourhood problems (odds ratio: 1.61), substance abuse (odds ratio: 1.49), having a severe or profound disability (odds ratio: 1.31) and living in a household with someone who has been charged with an offence (odds ratio: 1.15). Other variables with high odds ratios were social stress (odds ratio: 1.94), financial stress (odds ratio: 1.69) and unemployment (odds ratio: 1.21), being a member of the stolen generation (odds ratio: 1.71), being a lone parent (odds ratio: 1.39) and number of dwellings in the previous 12 months (odds ratio: 1.33). In the bi-variate analyses, having difficulties with English, living in traditional homelands, living in a remote rural area and identifying with a clan group or speaking an Indigenous language all showed a higher prevalence of victimisation. None of these variables remained significant in the presence of controls for lifestyle, social deprivation and social disorganisation factors.

The lack of support for cultural theories of violence is surprising given the anthropological evidence on Indigenous violence. However there were three features in the Snowball and Weatherburn (2008) study that might have obscured the effect of Indigenous cultural attachment on risk of violent victimisation. The first is that our measure of cultural attachment relied on simple 'yes' or 'no' answers to questions dealing with whether or not the respondent had difficulties with English, lived in traditional homelands, identified with a clan group or spoke an Indigenous language. We assumed that respondents who answered 'yes' to these questions are more 'attached' to traditional culture than respondents who answered 'no'. While this is not an unreasonable assumption, it could be argued that attachment to traditional Indigenous culture is signalled as much by participation in cultural activities, events, ceremonies and organisations as it is by language, clan membership and residence. Our measure of cultural attachment was insensitive to this participation. The second problem is that the NATSISS data in our 2008 study were analysed without regard to residential location. This is an important limitation because the effects of cultural attachment may be limited to Indigenous Australians living in remote Australia, where most of the anthropological research on Indigenous violence has been conducted. Lumping remote and non-remote respondents together in the one analysis when most $(65.2 \%)$ NATSISS respondents live in non-remote areas may have obscured the effects of cultural attachment. The final limitation in our study was that the question on violent victimisation in the 2002 NATSISS captured both threats of violence and actual violence. Cultural attachment may have stronger effects on the actual incidence of violence than on threats of violence, which may not have any ritualistic dimension (although see Sutton 2009: 92).

Given the limitations just mentioned and the apparent conflict between our earlier findings and those of anthropologists, it seems appropriate to conduct a further assessment of the relevance of cultural theories of violence. In the 
present study we attempt to improve on Snowball and Weatherburn (2008) in three ways. First we construct a more sensitive measure of cultural attachment. This measure combines information from questions in the 2008 NATSISS dealing with whether the respondent spoke an Indigenous language; whether the respondent identified with a clan, cultural or language group; whether the respondent identified an area as their homeland or traditional country; whether the respondent presently lives in their homelands or traditional country; whether the respondent participated in selected cultural activities in the preceding 12 months and whether the respondent was involved in cultural events, ceremonies or organisations in the preceding 12 months. Second, rather than define a victim of violence as someone who has experienced either a threat of violence or actual violence, we restrict our definition of a victim of violence to someone has been physically assaulted (not merely threatened) in the preceding 12 months. Thirdly and most importantly, we construct separate models for remote and non-remote respondents. This should give us a better chance of picking up the effects of Indigenous culture if they are confined to remote areas. In the next section we describe the methods used in greater detail.

\section{Methodology}

The data from the 2008 NATSISS were collected by the ABS between August 2008 and April 2009 and involved interviews with Indigenous people of all ages. The survey was administered in both community and non-community areas. In non-community areas 89 per cent of households responded to the screening question. The survey response rate in identified households was 83 per cent. In Indigenous communities (where no screening question was required) the survey response rate was 78 per cent. The coverage was 52.6 per cent which is relatively large when comparing with other ABS surveys. In total, 13307 Indigenous people in 6858 households were surveyed. This study was limited to those aged over 18 at the time of the survey, which constituted 53.8 per cent of the sample (7163 respondents). Five respondents refused to answer the question on victimisation and therefore were removed from the sample, leaving 7158 respondents in the final sample. The victimisation rate in this sample was 14.7 per cent (1,054 respondents) unweighted. The weighted rate was 19.8 per cent.

\section{Variable selection}

The dependent variable was whether the respondent was a victim of physical violence in the preceding 12 months. As noted earlier, cultural attachment was measured using responses to the following questions:

- whether the respondent spoke an Indigenous language 
- whether the respondent identified with a clan, cultural or language group

- whether the respondent identified an area as homelands/traditional country

- whether the respondent presently lives in homelands/traditional country

- whether the respondent participated in selected cultural activities in the preceding 12 months

- whether the respondent was involved in cultural events, ceremonies or organisations in the preceding 12 months.

The total number of positive responses to the above questions was determined for each person (with 0 being the minimum possible score and 6 being the maximum). Then each person was classified as low (score of 0,1 or 2 ) or high (score of $3+$ ).

Because of the relatively small sample size in the remote grouping we were unable to include a large number of variables in the final model. The variables included as controls in the present analysis were all significant in our previous analysis (Snowball and Weatherburn 2008) and had high parameter values, suggesting they were important factors in victimisation. Three variables that had a high parameter value and were significant in the previous modelling however, were not included. These were 'first charged as a child', 'neighbourhood problems' and 'social involvement'. The variable 'first charged as a child' was excluded because its theoretical significance is uncertain and its inclusion in the present analysis made little difference to the results. The 'neighbourhood problem' variable was not included because of a concern that the response to this question could be influenced by the response to the question of victimisation. That is, if you had been the victim of violence you could be more likely to report that you lived in an unsafe area. The social involvement variable was not included because involvement in activities forms part of the culture variable. The other variables included in the study, therefore, were:

- Stressors: Whether or not the respondent personally experienced one or more of a list of stressors in the preceding 12 months. The stressors used in measuring this variable were limited to death of a family member or close friend; not able to get a job; lost a job/sacked/made redundant/retired; treated badly/discrimination. The variable was coded ' 1 ' if experienced one or more stressors and ' 0 ' otherwise.

- Financial stress: Whether or not the respondent experienced financial stress in the previous 12 months (as indexed by responses to the question 'Whether the household members ran out of money for basic living expenses in the preceding 12 months'. The variable was coded ' 1 ' if experienced one or more stressors and ' 0 ' otherwise.

- Age: The age of the respondent, coded ' 1 ' if aged under 25, '0' if 25 or over. 
- Gender: The gender of the respondent, coded ' 1 ' if the victim was male; ' 0 ' if female.

- Alcohol use: Whether the respondent was identified as a high risk alcohol consumer in the preceding 12 months, coded ' 1 ' if a high risk alcohol consumer and ' 0 ' otherwise;

- Substance use: Whether the respondent used substances which were nonmedically prescribed in the preceding 12 months, coded ' 1 ' if the respondent had used substances, '0' otherwise.

- Lone parent: Whether the respondent lived in a lone parent household, coded ' 1 ' if the respondent lived in a lone parent household, ' 0 ' otherwise.

- Moved: Whether the respondent had moved in the preceding 12 months, coded ' 1 if the respondent had moved and ' 0 ' otherwise.

- Stolen Generation: Whether the respondent or a member of their family were part of the stolen generation, coded ' 1 ' if the respondent was a member of the stolen generation and ' 0 ' otherwise.

- Family type: Whether the household was a lone parent household, coded ' 1 ' if a lone parent household and ' 0 ' otherwise.

Again as noted earlier, the analysis was carried out separately for remote and non-remote respondents - where remoteness was defined using the Australian Standard Geographical Classification (ASGC). Firstly the bivariate relationship between violent victimisation and the independent variables was the examined. Then the dependent variable was regressed against the independent variables in a logistic model. Where there were missing values for the independent variables a separate and additional variable was created comparing the reference category to 'not stated' (e.g. substance abuse vs no substance abuse and substance abuse vs substance abuse not stated). This variable was then included in the model to avoid losing substantial information. Variables (including the 'not stated' variables) were only retained in the final model if they were significant.

\section{Results}

The number of respondents with characteristics used in the model as well as the corresponding weighted percentage are given in Tables 11.1a and 11.1b. The third column gives the number of non stated responses for that variable. 
Survey Analysis for Indigenous Policy in Australia

Table 11.1a Frequencies for the non-remote sample, Indigenous Australia, 2008

\begin{tabular}{|c|c|c|c|c|}
\hline \multicolumn{2}{|l|}{ Variable } & \multirow{3}{*}{$\begin{array}{r}\begin{array}{r}\text { Number of } \\
\text { respondents }\end{array} \\
863 \\
3829\end{array}$} & \multirow{3}{*}{$\begin{array}{r}\begin{array}{r}\text { Weighted } \\
\text { percentage }\end{array} \\
23.61 \\
76.39\end{array}$} & \multirow{3}{*}{$\begin{array}{r}\text { Number of } \\
\text { missing or } \\
\text { not stated } \\
- \\
-\end{array}$} \\
\hline Age & $18-24$ & & & \\
\hline & 25 and over & & & \\
\hline \multirow[t]{2}{*}{ Gender } & Female & 2702 & 52.95 & - \\
\hline & Male & 1990 & 47.05 & - \\
\hline \multirow{2}{*}{$\begin{array}{l}\text { Cultural } \\
\text { attachment }\end{array}$} & Low & 2660 & 56.25 & - \\
\hline & High & 2032 & 43.75 & - \\
\hline \multirow[t]{2}{*}{ Stressors } & Yes & 1759 & 38.54 & - \\
\hline & No & 2933 & 61.46 & - \\
\hline \multirow{2}{*}{$\begin{array}{l}\text { Financial } \\
\text { stress }\end{array}$} & Yes & 1315 & 28.14 & 25 \\
\hline & No & 3352 & 71.13 & 25 \\
\hline \multirow[t]{2}{*}{$\begin{array}{l}\text { Moved } \\
\text { location }\end{array}$} & Moved in preceding 12 months & 979 & 22.42 & - \\
\hline & $\begin{array}{l}\text { Has not moved in preceding } 12 \\
\text { months }\end{array}$ & 3713 & 77.58 & - \\
\hline \multirow[t]{2}{*}{$\begin{array}{l}\text { Stolen } \\
\text { generation }\end{array}$} & $\begin{array}{l}\text { Person or family member of } \\
\text { stolen generation }\end{array}$ & 2234 & 45.09 & 643 \\
\hline & Not member of stolen generation & 1815 & 41.76 & 643 \\
\hline \multirow[t]{2}{*}{ Family type } & Lone parent family & 1229 & 26.98 & - \\
\hline & Other & 3463 & 73.02 & - \\
\hline \multirow[t]{2}{*}{$\begin{array}{l}\text { Substance } \\
\text { abuse }\end{array}$} & Yes & 2257 & 45.92 & 363 \\
\hline & No & 2072 & 44.91 & 363 \\
\hline \multirow[t]{2}{*}{ Alcohol use } & High risk alcohol use & 312 & 7.29 & 55 \\
\hline & No high risk alcohol use & 4380 & 92.47 & 55 \\
\hline
\end{tabular}

Source: Authors' calculations using the 2008 NATSISS (accessed using the RADL) 
11. Is there a cultural explanation for Indigenous violence? A second look at the NATSISS

Table 11.1b Frequencies for the remote sample, Indigenous Australia, 2008

\begin{tabular}{|c|c|c|c|c|}
\hline \multicolumn{2}{|l|}{ Variable } & \multirow{2}{*}{$\begin{array}{r}\begin{array}{r}\text { Number of } \\
\text { respondents }\end{array} \\
2040\end{array}$} & \multirow{3}{*}{$\begin{array}{r}\begin{array}{r}\text { Weighted } \\
\text { percentage }\end{array} \\
21.18 \\
78.82\end{array}$} & \multirow{3}{*}{$\begin{array}{r}\text { Number of } \\
\text { missing or } \\
\text { not stated } \\
- \\
-\end{array}$} \\
\hline Age & $18-24$ & & & \\
\hline & 25 and over & 431 & & \\
\hline \multirow[t]{2}{*}{ Gender } & Female & 1384 & 51.93 & - \\
\hline & Male & 1087 & 48.07 & - \\
\hline \multirow[t]{2}{*}{$\begin{array}{l}\text { Cultural } \\
\text { attachment }\end{array}$} & Low & 579 & $22 . .17$ & - \\
\hline & High & 1892 & 77.83 & - \\
\hline \multirow[t]{2}{*}{ Stressors } & Yes & 956 & 38.76 & - \\
\hline & No & 1515 & 61.24 & - \\
\hline \multirow[t]{2}{*}{$\begin{array}{l}\text { Financial } \\
\text { stress }\end{array}$} & Yes & 682 & 27.64 & 21 \\
\hline & No & 1768 & 71.86 & 21 \\
\hline \multirow[t]{2}{*}{$\begin{array}{l}\text { Moved } \\
\text { location }\end{array}$} & Moved in preceding 12 months & 544 & 20.87 & - \\
\hline & $\begin{array}{l}\text { Has not moved in preceding } 12 \\
\text { months }\end{array}$ & 1927 & 79.13 & - \\
\hline \multirow[t]{2}{*}{$\begin{array}{l}\text { Stolen } \\
\text { generation }\end{array}$} & $\begin{array}{l}\text { Person or family member of stolen } \\
\text { generation }\end{array}$ & 885 & 33.33 & 235 \\
\hline & Not member of stolen generation & 1351 & 57.12 & 235 \\
\hline \multirow[t]{2}{*}{ Family type } & Lone parent family & 636 & 74.31 & - \\
\hline & Other & 1835 & 25.69 & - \\
\hline \multirow[t]{2}{*}{$\begin{array}{l}\text { Substance } \\
\text { abuse }\end{array}$} & Yes & 719 & 28.48 & 212 \\
\hline & No & 1540 & 62.31 & 212 \\
\hline \multirow[t]{2}{*}{ Alcohol use } & High risk alcohol use & 168 & 6.00 & 18 \\
\hline & No high risk alcohol use & 2303 & 93.33 & 18 \\
\hline
\end{tabular}

Source: Authors' calculations using the 2008 NATSISS (accessed using the RADL) 
Survey Analysis for Indigenous Policy in Australia

Table 11.2 gives the victimisation rates for the variables of interest for nonremote and remote Indigenous Australians. Note that the rates are weighted.

Table 11.2 Victimisation rates by area, Indigenous Australia, 2008

\begin{tabular}{|c|c|c|c|}
\hline \multicolumn{2}{|l|}{ Variable } & Non-remote (\%) & Remote (\%) \\
\hline Age & $18-24$ & 21.1 & 23.5 \\
\hline & 25 or over & 12.6 & 10.7 \\
\hline \multirow[t]{2}{*}{ Gender } & Female & 14.6 & 13.0 \\
\hline & Male & 14.6 & 14.2 \\
\hline \multirow[t]{2}{*}{$\begin{array}{l}\text { Cultural } \\
\text { attachment }\end{array}$} & & 12.5 & \\
\hline & High & 17.3 & 13.8 \\
\hline \multirow[t]{2}{*}{ Stressors } & Yes & 22.3 & 18.3 \\
\hline & No & 9.7 & 10.6 \\
\hline \multirow[t]{2}{*}{$\begin{array}{l}\text { Financial } \\
\text { stress }\end{array}$} & & 20.7 & 19.1 \\
\hline & No & 12.1 & 11.3 \\
\hline \multirow[t]{2}{*}{$\begin{array}{l}\text { Moved } \\
\text { location }\end{array}$} & Moved in preceding 12 months & 23.9 & 17.7 \\
\hline & Has not moved in preceding 12 months & 11.9 & 12.5 \\
\hline \multirow[t]{2}{*}{$\begin{array}{l}\text { Stolen } \\
\text { generation }\end{array}$} & $\begin{array}{l}\text { Person or family member of stolen } \\
\text { generation }\end{array}$ & 19.0 & 18.9 \\
\hline & Not member of stolen generation & 11.1 & 9.9 \\
\hline \multirow[t]{2}{*}{ Sole parent } & Yes & 20.4 & 15.5 \\
\hline & Other & 12.4 & 12.9 \\
\hline \multirow[t]{2}{*}{$\begin{array}{l}\text { Substance } \\
\text { abuse }\end{array}$} & Yes & 21.2 & 23.3 \\
\hline & No & 8.4 & 8.2 \\
\hline \multirow[t]{2}{*}{ Alcohol use } & High risk alcohol use & 27.4 & 29.4 \\
\hline & No high risk alcohol use & 13.6 & 12.6 \\
\hline Total & & 14.6 & 13.6 \\
\hline
\end{tabular}

Source: Authors' calculations using the 2008 NATSISS (accessed using the RADL)

Table 11.2 suggests the following are related to higher levels of victimisation in both non-remote and remote areas:

- younger ages

- high risk alcohol use

- substance abuse

- family removal

- living in a lone parent household

- stressors 
- financial stress

- moved in the previous year

- high cultural attachment (only in non-remote areas).

Males and females have similar levels of victimisation in both areas. Tables 11.3a and $11.3 \mathrm{~b}$ give the results of the logistic regression modelling for the non-remote and remote sample. Gender was not included in any of the models because of the results of the bivariate analysis. Positive coefficients suggest that the variable is related to higher levels of victimisation. An asterisk denotes a significant variable. Three models were developed for each area. The first contained the age variable and the cultural attachment variables. The second model contained the variables of Model 1 with the addition of the stressors and financial stress variables. The final model contained all the variables that were significant.

Table 11.3a Logistic models for the non-remote sample

\begin{tabular}{|l|c|c|c|}
\hline \multicolumn{1}{|c}{$\begin{array}{c}\text { Parameter value } \\
\text { (and standard error) }\end{array}$} & \multicolumn{1}{c}{$\begin{array}{c}\text { Parameter value } \\
\text { (and standard error) }\end{array}$} & \multicolumn{1}{c|}{$\begin{array}{c}\text { Parameter value } \\
\text { (and standard error) }\end{array}$} \\
\hline Intercept & $-2.0(0.06)^{*}$ & $-2.5(0.08)^{*}$ & $-3.23(0.11)^{*}$ \\
\hline Under 25 vs 25 or over & $0.60(0.10)^{*}$ & $0.57(0.10)^{*}$ & $0.40(0.10)^{*}$ \\
\hline $\begin{array}{l}\text { Low cultural attachment } \\
\text { vs High cultural } \\
\text { attachment }\end{array}$ & $0.33(0.08)^{*}$ & $0.21(0.01)^{*}$ & $0.13(0.15)$ \\
\hline Stressors vs No stressors & & $0.59(0.08)^{*}$ & $0.48(0.09)^{*}$ \\
\hline $\begin{array}{l}\text { Financial stress vs } \\
\text { No financial stress }\end{array}$ & & $0.87(0.09)^{*}$ & $0.62(0.09)^{*}$ \\
\hline $\begin{array}{l}\text { Family removal vs } \\
\text { No family removal }\end{array}$ & & & $0.36(0.09)^{*}$ \\
\hline $\begin{array}{l}\text { High risk alcohol vs } \\
\text { No high risk alcohol }\end{array}$ & & & $0.76(0.14)^{*}$ \\
\hline $\begin{array}{l}\text { Substance abuse vs } \\
\text { No substance abuse }\end{array}$ & & & $0.63(0.09)^{*}$ \\
\hline $\begin{array}{l}\text { Moved in last 12 months } \\
\text { vs Has not moved }\end{array}$ & & & $0.52(0.10)^{*}$ \\
\hline $\begin{array}{l}\text { Lone parent vs } \\
\text { Other family type }\end{array}$ & & & $0.09)^{*}$ \\
\hline
\end{tabular}

Source: Authors' calculations using the 2008 NATSISS (accessed using the RADL) 
Survey Analysis for Indigenous Policy in Australia

Table 11.3b Logistic models for the remote sample

\begin{tabular}{|l|c|c|c|}
\hline \multicolumn{1}{|c}{$\begin{array}{c}\text { Parameter value } \\
\text { (and standard error) }\end{array}$} & \multicolumn{1}{c}{$\begin{array}{c}\text { Parameter value } \\
\text { (and standard error) }\end{array}$} & \multicolumn{1}{c|}{$\begin{array}{c}\text { Parameter value } \\
\text { (and standard error) }\end{array}$} \\
\hline Intercept & $-2.03(0.13)^{*}$ & $-2.53(0.10)^{*}$ & $-3.10(0.13)^{*}$ \\
\hline Under 25 vs 25 or over & $0.82(0.13)^{*}$ & $0.84(0.14)^{*}$ & $0.84(0.14)^{*}$ \\
\hline $\begin{array}{l}\text { Low cultural attachment } \\
\text { vs High cultural } \\
\text { attachment }\end{array}$ & $0.02(0.14)$ & & \\
\hline $\begin{array}{l}\text { Stressors vs } \\
\text { No stressors }\end{array}$ & & $0.67(0.12)^{*}$ & $0.53(0.12)^{*}$ \\
\hline $\begin{array}{l}\text { Financial stress vs } \\
\text { No financial stress }\end{array}$ & & $0.63(0.12)^{*}$ & $0.54(0.13)^{*}$ \\
\hline $\begin{array}{l}\text { Family removal vs } \\
\text { No family removal }\end{array}$ & & & $0.40(0.13)^{*}$ \\
\hline $\begin{array}{l}\text { High risk alcohol vs } \\
\text { No high risk alcohol }\end{array}$ & & & $0.91(0.19)^{*}$ \\
\hline $\begin{array}{l}\text { Substance abuse vs } \\
\text { No substance abuse }\end{array}$ & & & $0.95(0.13)^{*}$ \\
\hline $\begin{array}{l}\text { Substance abuse not } \\
\text { stated vs No substance } \\
\text { abuse }\end{array}$ & & & $0.66(0.21)^{*}$ \\
\hline
\end{tabular}

Source: Authors' calculations using the 2008 NATSISS (accessed using the RADL)

In the non-remote models the cultural variable is significant after adjusting for age, stressors and financial stress. It is no longer significant at a $5 \%$ level $(\mathrm{p}$-value $=0.147)$, however, when the remaining variables are included in the model. Note also that in the first two models low cultural attachment is associated with higher levels of victimisation, which is a reverse of the bi-variate results. All other variables that were significant in the bivariate results are significant in the model and in the same direction. In the final model alcohol use is the strongest risk factor. Substance use, family type and financial stress, however, were all significant predictors of victimisation.

Cultural attachment is not significant in any of the remote area models, which confirms the bivariate results. The sole parent and moved variables are not significant in the final model - even though they were significant in the bivariate analysis. This could be due to the smaller sample size (and associated lower power).

To examine whether the variables behaved differently in each area we built a model with interactions based on the entire sample (so including both remote and non-remote respondents). The interaction between lone parent family and area was significant ( $\mathrm{p}$-value $=0.0037)$. The interaction between moved in previous 12 months and area was not significant although it had a relatively low p-value (0.0682). None of the other interactions were significant. 
The marginal effects for selected variables for the two areas are given in Table 11.4. The marginal effects are calculated for a person over the age of 25 with a zero value for all other characteristics. The base value is the probability of victimisation for a person with the base characteristics (over 25 with). The marginal effects are higher in the remote area model however this would be primarily due to the different variables in each model.

\section{Table 11.4 Marginal effects for selected variables for non-remote and remote area models}

\begin{tabular}{|l|r|r|}
\hline \multicolumn{2}{|c|}{ Non-remote areas (\%) } & Remote areas (\%) \\
\hline Base & 3.81 & 4.31 \\
+ Financial stress & 6.85 & 7.73 \\
+ Stressors & 6.01 & 6.79 \\
+ High risk alcohol & 7.80 & 8.79 \\
+ Substance abuse & 6.91 & 7.80 \\
\hline
\end{tabular}

Source: Authors' calculations using the 2008 NATSISS (accessed using the RADL)

In both models high risk alcohol significantly increases the probability of victimisation - by 3.99 per cent in non-remote areas and by 4.48 per cent in remote areas.

\section{Discussion}

The present results, like those in Snowball and Weatherburn (2008) provide little support for the hypothesis that Indigenous violence is a vestige of attachment to or involvement in traditional Indigenous cultural life. In fact the findings concerning cultural attachment are quite the opposite of what one would expect. Levels of cultural attachment and violence were related prior to controlling for other factors but only in non-remote areas. The association remained significant after adjusting significant after adjusting for age, stressors and financial stress but the sign on the coefficient reversed, suggesting that those with low cultural attachment actually had a higher risk of experiencing violence. One the full set of controls was introduced, cultural attachment ceased to be significant.

Although these findings appear to conflict with cultural explanations for Indigenous violence, the conflict may only be superficial. It is possible that culture played an important role in shaping the frequency, circumstances giving rise to and seriousness of Indigenous violence prior to colonisation but that other factors, such as alcohol abuse, have since come to the fore. In this vein it might also be argued that cultural attachment is more likely to affect the severity of Indigenous violence than it is to affect the probability of Indigenous 
violence. The possibility that there are cultural differences in the severity of Indigenous violence deserves serious consideration, given evidence that the injuries inflicted by Indigenous Australians on each other in central Australia have a ritualistic dimension (Jacob, Boseto and Ollapillil 2007). On the other hand, the 2008 NATISS data show no significant difference in the proportion of victims who were injured among those in the present study who scored high on level of attachment in traditional culture (55.7\% injured) compared with those who scored low in terms of attachment in traditional culture (58.7\% injured).

A second possibility is that cultural attachment affects the incidence of Indigenous violence rather than its prevalence. That is to say, Indigenous Australians who are culturally involved may be just as likely in the course of a year to experience a physical assault but much more likely to experience multiple assaults. This is also possible but it would be surprising to find marked differences in incidence of violence among groups differing in terms of their cultural attachment but and no difference at all in the prevalence of violence. A third possibility is that the effect of cultural attachment on Indigenous violence is hidden by cultural differences in the willingness to disclose an act of physical violence. Those who are more deeply involved in traditional Indigenous culture, in other words, may be more reluctant to disclose an act of violence or less inclined to view an act as violent as such, compared with those who are less deeply involved in traditional Indigenous culture. This is also possible but the ABS went to considerable trouble to ensure that the questions in the NATSISS survey were fully understood by respondents. The measures taken include extensive pretesting of survey questions in focus groups and, where necessary, the use of Indigenous interpreters. There was a slight difference in willingness to report assaults to police, with 50.5 per cent of respondents in the low cultural attachment category having reported the last assault to police, compared with 45.2 per cent of respondents who scored high in terms of attachment in traditional culture. Even if a similar difference existed in willingness to report violence to ABS interviewers, however, the difference the prevalence of violence between those who are strongly attached to traditional culture and those would not be very large. Taken as a whole, the evidence presented here provides little support for cultural theories of violence. As in our earlier study, high risk alcohol consumption, drug use, financial stress and social stress, are the strongest predictors of physical assault.

Some might be tempted to reject the evidence presented here on the grounds that our approach to measuring 'cultural attachment' is misleading and/or simplistic. We recognise that there are other ways of measuring 'cultural attachment' than the one we have chosen here. One might, for example, give more weight to some questions in the NATSISS than others or argue that cultural attachment is a complex construct, some features of which are conducive to violence in 
some situations and other features of which are conductive to restraint in other situations. We recognise the difficulty in turning an abstract concept like 'cultural attachment' into something that can quantified. It is impossible to test the 'cultural attachment' explanation for Indigenous violence, however, without making some assumptions about how to measure it. Indeed, if the construct 'cultural attachment' cannot be measured in any way, it is hard to make any sense of the claim that Indigenous violence is a vestige of traditional Indigenous culture. It is, of course, entirely open to those who feel our measure of cultural attachment is misleading and/or simplistic to put forward an alternative measure. If the alternative measure of cultural attachment is plausible and yields very different results to those reported here, we shall be among the first to qualify our findings.

Like all observational studies of causal effects, the current study has a number of inherent limitations. The theories we have been testing are theories about violent offending, not violent victimisation. We have measured victim characteristics (e.g. cultural attachment, alcohol consumption, financial stress) on the assumption that they are shared by offenders. This assumption is open to question. Our conclusions would have been stronger and more compelling if we had been able to analyse the correlates of self-reported violent offending rather than the correlates of self-reported violent victimisation. It is to be hoped, for this reason, that the next iteration of the NATSISS includes questions on selfreported involvement in violence (and other offending). A second and related limitation is that it is impossible to be sure in a cross-sectional study such as the NATSISS that the putative causes (e.g. alcohol consumption, financial stress) actually pre-date the effects (violence). While there is little doubt that alcohol use increases the risk of violence, some of what we see as the effect of alcohol use on violence may actually be a reflection of the effect of violence on alcohol use. The only way to properly test claims about causation is through longitudinal research. At present, unfortunately, cross-sectional data is all we have to go on. A third limitation is that the 2008 NATSISS has been heavily criticised for underestimating the prevalence of high risk Indigenous alcohol consumption (Chikritzhs and Brady 2006). The misclassification of high-risk Indigenous drinkers as non-high risk drinkers may have caused us to underestimate the strength of the association between Indigenous high-risk drinking and Indigenous violence.

\section{Acknowledgements}

We would like to thank our anonymous reviewers for the careful and constructive feedback they provided on an earlier draft of this chapter. 


\section{References}

Australian Bureau of Statistics (ABS) 2004. National Aboriginal and Torres Strait Islander Social Survey, 2002, cat. no. 4714.0, ABS, Canberra.

2010. National Aboriginal and Torres Strait Islander Social Survey, 2008, cat no. 4714.0, ABS, Canberra.

Chikritzhs, T. and Brady, B. 2006. 'Fact or fiction? A critique of the National Aboriginal and Torres Strait Islander Social Survey 2002', Drug and Alcohol Review, 25 (3): 277-87.

Clapham, K. F., Stevenson, M. R. and Lo, S. K. 2006. 'Injury profiles of Indigenous and non-Indigenous people in New South Wales', Medical Journal of Australia, 184 (5): 217-20.

Cohen, L. E. and Felson, M. 1979. 'Social change and crime rate trends: A routine activity approach', American Sociological Review, 44: 588-608.

Commonwealth of Australia 1991. Royal Commission into Aboriginal Deaths in Custody, Commonwealth of Australia, Canberra.

Devery, C. 1991. Disadvantage and Crime in New South Wales, NSW Bureau of Crime Statistics and Research, Sydney.

Fitzgerald, J. and Weatherburn, D. 2001. 'Aboriginal victimisation and offending: The picture from police records', Bureau Brief December 2001, NSW Bureau of Crime Statistics and Research, Sydney.

Gale, F., Bailey-Harris, R. and Wunderitz, J. 1990. Aboriginal Youth and the Criminal Justice System, Cambridge University Press, Cambridge.

Harding, R., Broadhurst, R., Ferrante, A. and Loh, N. 1995. Aboriginal Contact with the Criminal Justice System and the Impact of the Royal Commission into Aboriginal Deaths in Custody, The Hawkins Press, Sydney.

Hughes, H. and Warin, J. 2005. 'A new deal for Aborigines and Torres Strait Islanders in remote communities', Issue Analysis No. 54, Centre for Independent Studies, Sydney.

Hunter, E. 1993. Aboriginal Health and History, Cambridge University Press, Cambridge.

Jacob, A. O., Boseto, F. and Ollapallil, J. 2007. 'Epidemic of stab injuries: An Alice Springs dilemma', Australian and New Zealand Journal of Surgery, 77: 621-25. 
Langton, M. 1988. 'Medicine square', in I. Keen (ed.), Being Black, Aboriginal Studies Press, Canberra.

Martin, D. F. 1992. 'Aboriginal and non-Aboriginal homicide: Same but different', in H. Strang and S. Gerull (eds), Homicide: Patterns, Prevention and Control, Australian Institute of Criminology, Canberra.

Pearson, N. 2001. 'On the human right to misery, mass incarceration and early death', The Charles Perkins Memorial Oration, University of Sydney, 25 October, viewed 5 October 2011, available at <http://sydney.edu.au/koori/ news/pearson.pdf>

Reser, J. 1990. 'A perspective on the causes and cultural context of violence in Aboriginal communities in north Queensland', Report to the Royal Commission into Aboriginal Deaths in Custody, James Cook University of North Queensland, Townsville.

Sampson, R. J., Raudenbush, S. W. and Earls, F. 1997. 'Neighbourhoods and violent crime: A multi-level study of collective efficacy', Science, 277 (5328): 918-24.

Snowball, L. and Weatherburn, D. 2008. 'Theories of Indigenous violence: A preliminary empirical assessment', Australian and New Zealand Journal of Criminology, 41 (2): 216-35.

Sutton, P. 2001. 'The politics of suffering: Indigenous policy in Australia since the 1970s', Anthropological Forum, 11 (2): 125-69.

2009. The Politics of Suffering: Indigenous Australia and the End of the Liberal Consensus, Melbourne University Press, Melbourne.

Wilson, C., Nettelbeck, T., Potter, R. and Perry, C. 1996. Intellectual Disability and Criminal Victimisation, Trends and Issues in Crime and Criminal Justice No. 60, Australian Institute of Criminology, Canberra. 